\title{
WHICH FACTORS ARE INFLUENCING ARTISTIC SWIMMING PERFORMANCE?
}

\author{
Stavroula Ntomali ${ }^{1 \mathrm{i}}$, \\ Manolis Adamakis², \\ Fotini Venetsanou', \\ Chrysoula Chairopoulou, ${ }^{1}$, \\ Maria Psychountaki ${ }^{1}$ \\ ${ }^{1}$ School of Physical Education \& Sports Science, \\ National and Kapodistrian University of Athens, \\ Greece \\ ${ }^{2}$ School of Education, \\ University College Cork, \\ Ireland
}

\begin{abstract}
:
Rhythmic ability (RA) plays an important role in sports in which music accompaniment is used, such as artistic swimming (AS). The aim of the present study was to investigate RA's relationship with the athletes' overall performance in AS, as well as the independent scores of AS performance (i.e., Execution, Artistic Impression and Difficulty), taking into account their competitive category and experience. The sample consisted of 47 female artistic swimmers (age 15.8 \pm 3.3 years; athletic experience $6.6 \pm 3.3$ years) divided into three competitive categories (Senior, Junior, and Comen). The High/Scope Rhythmic Competence Analysis Test (Weikart, 1989) was used for the evaluation of RA of participants. Three official AS judges were used to assess athletes' performance in the water routine session. Descriptive and inferential (i.e., two MANCOVAs) statistical analysis revealed that experience was a significant positive predictor of AS Performance and RA, indicating that as experience increased, athletes' AS performance and RA also increased. In addition, results showed that athletes in the senior category scored higher in all variables in relation to junior and comen athletes; however, these differences were not statistically significant.
\end{abstract}

Keywords: artistic swimming, rhythmic ability, performance, athletic experience, FINA

i Correspondence: email sdomali@phed.uoa.gr 


\section{Introduction}

Rhythm is an essential component of every human activity (Oreb \& Kilibarda, 1996), affecting not only the acquisition and performance of motor skills (Thomas \& Moon, 1976), but also academic achievement (Kuhlman \& Schweinhart, 1999) and personal development (Thomas \& Moon, 1976). It is also an integrated feature of dance (Laurence, 2000; Vaculíková et al., 2011) and most (if not all) sports (e.g., Bago, Hedbavny, \& Kalichova, 2013; Borysiuk \& Waskiewicz, 2008; Bourquin, 2003; Das, 2013; Söğüt, Kirazci \& Korkusuz, 2012; Weikart, 1989). Thus, rhythm is noticeable, for example in swimming, where athletes get their own beat by moving their arms and legs in a coordinated pattern of strokes and kicks (Weikart, 1989); in fencing, with fencers' footwork rhythm providing information about the distance between the fighting opponents (Borysiuk \& Waskiewicz, 2008; and in tennis, where athletes perform harmonious movements (Bourquin, 2003; Söğüt et al., 2012).

It is well known that rhythmic ability (RA), i.e., "the ability to perform a succession of regulated, recurring gross motor events requiring both spatial and temporal accuracy" (Thomas \& Moon, 1976; p. 21), is considered very important in dance, where movements are performed in a rhythmic structure and are affected by rhythm elements (Kirchner \& Fishburne, 1995). Apart from dance, a large amount of research underlines the significant role of RA in sports, such as fencing (Borysiuk \& Waskiewicz, 2008), volleyball (Pollatou et al., 2005), racquet sports (badminton, table tennis; Thapa et al., 2016), tennis (Bourquin, 2003; Schönborn, 2003; Segal, 2005; Zachopoulou et al., 2000), swimming (Huff, 1972; Weikart, 1989; Zachopoulou et al., 2000), alpine skiing (Oreb et al., 2011), dance (Kirchner \& Fishburne, 1995; Vaculíková et al., 2011), gymnastics (Pica, 1998), karate (Takahata et al., 2004) and basketball (Derri, Kioumourtzoglou, \& Tzetzis, 1998; Kioumourtzoglou et al., 1998; Mastrokalou \& Hatziharistos, 2007; Pollatou et al., 2005; Southard \& Miracle, 1993; Wrisberg \& Pein, 1992; Zachopoulou et al., 2000).

Although in a few studies, athletes and non-athletes (Kioumourtzoglou et al., 1998; Schwanda, 1969), or different level athletes (Sardar, \& Verma, 2014), were found to have similar RA levels, RA is considered as one of the basic abilities of an athlete (Zachopoulou et al., 2000). Several researchers have revealed that athletes surpassed non-athletes in RA measurements (Söğüt \& Kirazci, 2014; Zachopoulou et al., 2000) with the well-trained ones presenting higher levels of RA (Benton, 1944; Haight, 1944; Huff, 1972). In the study of Huff (1972), in which RA of 22 dancers was compared with that of 35 high level athletes of different sports and 32 non-athletes, it was found that skilled dancers, swimmers, tennis players, and the combined group of skilled athletes performed significantly better than non-athletes in RA tests. Apart from athletes' competitive level, RA is associated with age, improving as the individual is growing up (Haskell, 1993; Kumai \& Sugai, 1997; Rainbow, 1981; Rosenbusch \& Gardner, 1968; Schleuter \& Schleuter, 1985).

As it can be expected, RA plays an important role in sports in which music accompaniment is used, such as artistic swimming (AS). AS is an Olympic sport that includes swimming skills, figures and a combination of swimming, dance and gymnastics. In fact, AS can be described as ballet in water. Artistic swimmers execute 
rhythmic movements in the water, shapes in and under water and very often acrobatic moves (Chairopoulou, 2010). Usually, athletes of AS select musical pieces that have different characteristics from fast to slow and the opposite so that attract both the audience and the judges. This puts an additional difficulty to the athletes of AS, since it is known that someone's ability to be rhythmically accurate and to maintain a steady rhythm in movement execution is affected by the tempo of the external stimuli (music or other sounds), with individuals performing significantly better during fast tempos compared to slow one's (Ellis, 1992; Mastrokalou \& Hatziharistos, 2007; Rao, Mayer, \& Harrington, 2001; Söğüt et al., 2012; Zachopoulou, 1998; Zachopoulou et al., 1999). Music interpretation is of the most important characteristics of AS, because swimmers must synchronize their movements to each other and also to the rhythm, mood, and intensity of the music (Mountjoy, 2009). All positions, figures, transitions and movements should be performed with precise synchronization to solos, duets or teams either to free or technical routines. AS judges award a mark out of 10, based on the above criteria and also for the level of difficulty, execution, choreography and the manner of presentation, according to Federation Internationale de Natation (FINA) rules 2017-2021 (FINA, 2017).

Taking the above into consideration, it is obvious that RA is very important ability for AS, significantly contributing to the score an athlete achieves. Thus, assessing athletes' RA and examining its association with other factors, such as their experience, competitive category and artistic swimming performance, would provide useful information that could contribute to the improvement of the quality of AS athletes' long term athletic training. Nevertheless, there are not published studies investigating AS athletes' RA so far. On this basis, the aim of the present study was to investigate RA's relationship with the athletes' overall performance in AS, as well as the independent scores of AS performance (i.e., Execution, Artistic Impression and Difficulty), taking into account their competitive category and experience.

\section{Methods}

\subsection{Participants}

In total, 47 female artistic swimmers, aged 13-25 years (15.8 \pm 3.3 years) volunteered to participate in the study. All of them were active athletes, had at least two years of athletic experience and had been qualified for the Greek National Championship in their category. Seven of the swimmers were members of the Greek AS national team, whereas the rest participated only in national events. Moreover, athletes were classified into three competitive categories as Senior $(n=9 ; 21.7 \pm 2.1$ years), Junior $(n=7 ; 16.6 \pm 0.5$ years) and Comen ( $\mathrm{n}=31 ; 13.9 \pm 0.8$ years), according to the FINA AS rules (FINA, 2017). Before their participation in the study, all athletes were provided with written consent forms, which they had to fill out and sign on their own (if they were adults) or by their parents/guardians (if they were minors). The study was approved by the Ethics Committee of National and Kapodistrian University of Athens (protocol No: 1028/8/11/2017). 


\subsection{Measurements}

Information about participants' athletic profile was self-reported via a questionnaire. Moreover, the High/Scope Rhythmic Competence Analysis Test (Weikart, 1989) was used to assess athletes' RA in two different tempos, 120 and 130 beats per minute. The test is designed to evaluate an individual's ability to perform a motor sequence at a constant rate and consists of six movements: 1) Patting thighs with both hands at the same time in seated position; 2) Patting thighs alternating hands in seated position; 3) Walking the beat in place in seated position; 4) Walking the beat in place from standing position; 5) Walking the beat forward; and 6) Walking the beat backward. A standard metronome (DM - 8LT Intelli, accuracy +/- 0,2\%) was used for all tasks. A three-point scale (0, 1, and 2) was used for the assessment of each item. The examinee received a score of " 2 " when she could accurately match her movement to the underlying steady beat at least for 8 consecutive movements or more of 12 total beats. When the performance of the movement was consistent but not accurate to the beat for less than 8 consecutive beats, the examinee received a score of " 1 ". Finally, when the examinee could not achieve any of the above, received a score of " 0 ". The maximum score for the six movements was 12 points for each tempo (resulting to a total of 24 points). Two trained raters that were blind to each other scored each movement during the tests. Additionally, the process was videotaped in case of observers' disagreement using a Sony HDR-PJ410. Regarding the psychometric properties of the High/Scope Beat Competence Analysis Test, it presents sufficient internal consistency (Weikart et al., 1987), test-retest reliability (Agdiniotis et al., 2009; Derri et al., 2001; Liapa, 2004; Pollatou et al., 2005; Söğüt \& Kirazci, 2014), and concurrent validity, shown by its statistically significant, positive correlations with the Test of Gross-Motor Ability (Kiger, 1994).

For the athletes' performance evaluation three judges were used. During a routine session, the judges were placed in elevated positions on the opposite sides of the swimming pool, always keeping distance between themselves. Three scores were used: 1) Execution (execution, synchronization); 2) Artistic Impression (choreography, music interpretation, manner of presentation); and 3) Difficulty (of all movements and synchronization). The scores were computed in a scale from 0 to 10 , with increments of 10, according to FINA rules (FINA, 2017). As the agreement between judges was found to be excellent, ranging from $r=0.987$ to 0.993 , the total sum each athlete received was the three judges' average score. The routine that the athletes performed with music was the same for everyone that participated in the measurement. It included swimming styles, movements with hands, boost with both hands out of the water, surface moves, travelling ballet leg, basic positions, transitions and part or entire figures of AS like Rio, Porpoise Continuous Spin $720^{\circ}$, Aurora Twirl, Whirlwind, Vertical Twist Spin (FINA, 2017).

\subsection{Procedure}

Initially, a briefing was held in AS clubs, in which coaches and athletes were informed about the purpose and the procedures of the study, both verbally and in a written form. Only those who provided a written consent form took part in the study. 
Then the High/Scope Beat Competence Analysis Test was administered to the artistic swimmers individually, in a silent room of the swimming hall, without the presence of other athletes or coaches, according to its manual guidelines (Weikart, 1989). Two trained raters, who were blind to each other, scored each item. Additionally, the process was videotaped in case of observers' disagreement using a Sony HDR-PJ410. The inter-rater reliability was checked before measurements and found to be excellent for both the slow (agreement range: 91.0-100\%) and the fast tempo (agreement range: 97.9$100 \%$ ). Thus, the average score of the two raters was used in the analyses.

Subsequently, the athletes had a warm-up session in the water, which included swimming laps and choreography. In addition, they performed the routine individually. The routine execution order was decided by draw. When the athlete positioned at the starting place, the researcher gave the signal to the Sound Center Manager to start the music. For the reproduction of music, two underwater speakers (Oceanears) on each side of the swimming pool, were used. Warm-up and music were the same for all athletes. At the completion of each routine, the judges recorded their scores on judging papers that were collected directly after each athlete's performance.

\subsection{Statistical analysis}

Data were analysed through descriptive (mean, standard deviation) and inferential statistics [multivariate analysis of covariance (MANCOVA)]. Two MANCOVAs were performed. In the first one, the independent variable was Category (Comen, Junior, and Senior), and the dependent variables were the three main categories of AS Performance (Execution, Artistic Impression and Difficulty), while Experience and RA were included in the model as covariates. In the second MANCOVA, the independent variable was once more Category, the dependent variables were AS Performance and RA, and Experience was included in the model as covariate. To control whether the design was unbalanced, the equality of covariance matrices using Box's M test was used. Furthermore, the partial $\eta^{2}$ was presented as a measure of effect size for F-Tests. A partial $\eta^{2}$ value between 0.01 and 0.06 was associated with a small effect, between 0.06 and 0.14 with a medium effect, and 0.14 or greater with a large effect (Warner, 2013). For purposes of interpretation, significant multivariate effects were followed by univariate F-ratios [analysis of variance (ANOVA)] with Bonferroni corrected values, as well as multiple regressions for the covariates. The significance level for all analyses was set at $\mathrm{p}<0.05$. Due to the fact that the sample sizes in the independent variables were not equal, the Pillai's Trace criterion was selected for interpretation purposes, as this criterion is more robust in small and unequal sample sizes (Ateş et al., 2019; Olson, 1974; Tabachnick \& Fidell, 2013). All statistical analyses were conducted with the use of the statistical package SPSS version 26.0 (IBM SPSS Corp., Armonk, NY, USA).

\section{Results}

Results showed that most athletes were in the Comen category $(66.0 \%)$, followed by athletes in the Senior (19.1\%) and Junior (14.9\%) categories. In addition, most athletes 
have participated in national competitions (85.1\%). Athletes' average athletic experience was $6.62 \pm 3.35$ years and the average number of competitions they have participated was 14.7 \pm 18.9 . Descriptive statistics for all variables, according to the various categories (Senior, Junior, and Comen), are presented in Table 1.

Table 1: Descriptive statistics for Execution, Artistic Impression, Difficulty, Rhythmic Ability and Artistic Swimming Performance, according to Category

\begin{tabular}{llcccc}
\hline Variables & Category $(\mathbf{n})$ & $\mathbf{M}$ & SD & min-max & Range \\
\hline \multirow{3}{*}{ Execution } & Senior (9) & 7.87 & 0.93 & $5.87-8.87$ & 3.00 \\
\cline { 2 - 5 } & Junior (7) & 5.48 & 0.69 & $4.77-6.57$ & 1.80 \\
\cline { 2 - 5 } Artistic Impression & Comen (31) & 5.86 & 1.07 & $3.73-7.33$ & 3.60 \\
\hline \multirow{3}{*}{ Difficulty } & Senior & 7.94 & 0.88 & $5.93-9.03$ & 3.10 \\
\cline { 2 - 5 } & Junior & 5.47 & 0.68 & $4.73-6.57$ & 1.83 \\
\cline { 2 - 5 } & Comen & 5.87 & 1.05 & $3.90-7.43$ & 3.53 \\
\hline \multirow{3}{*}{ Artistic Swimming Performance } & Senior & 7.86 & 0.92 & $5.90-8.90$ & 3.00 \\
\cline { 2 - 5 } & Junior & 5.42 & 0.66 & $4.77-6.43$ & 1.67 \\
\hline \multirow{3}{*}{ Rhythmic Ability } & Comen & 5.86 & 1.04 & $3.87-7.40$ & 3.53 \\
\hline & Senior & 8.01 & 0.81 & $6.33-9.01$ & 2.68 \\
\cline { 2 - 5 } & Junior & 5.60 & 0.68 & $4.93-6.72$ & 1.79 \\
\cline { 2 - 5 } & Comen & 6.00 & 1.05 & $3.93-7.44$ & 3.51 \\
\hline & Senior & 23.83 & 0.35 & $23.00-24.00$ & 1.00 \\
\cline { 2 - 5 } & Junior & 20.86 & 2.55 & $16.50-23.50$ & 7.00 \\
\cline { 2 - 5 } & Comen & 21.97 & 1.73 & $17.50-24.00$ & 6.50 \\
\hline
\end{tabular}

For the first MANCOVA, the Box-M test of equality of covariance for the MANCOVA was not statistically significant (Box's $M=22.349, \mathrm{p}=0.103$ ) and the assumption that variance/covariance matrices are equal across two or more groups was met. The results indicated that statistically significant differences were observed between Categories [Pillai's Trace $\left.=0.346, F(6,80)=2.791, p=0.033, \eta^{2}=0.150\right]$ on the three dependent variables, however the separate ANOVA with Bonferroni adjustments did not yield statistically significant differences for Execution $\left[F(2,42)=1.745, \quad p=0.187, \eta^{2}=0.077\right]$, Artistic Impression $\left[F(2,42)=1.990, p=0.149, \eta^{2}=0.087\right]$ and Difficulty $[F(2,42)=2.061, p=0.140$, $\left.\eta^{2}=0.089\right]$ (Table 2). The initial differences were moderated by one of the covariates, Experience, which statistically significantly contributed to these differences [Pillai's Trace $=0.543, F(3,40)=15.866, p<0.001, \eta^{2}=0.543$, with large effect size, while RA was not a significant predictor [Pillai's Trace $=0.044, \mathrm{~F}(3,40)=0.614, \mathrm{p}=0.610, \eta^{2}=0.044$ ]. Experience, as a covariate, was a positive predictor of Execution $(B=0.328, p<0.001,95 \% \mathrm{CI}=0.226$ to 0.429 , $\left.\eta^{2}=0.502\right)$, Artistic Impression ( $B=0.317, \mathrm{p}<0.001,95 \% \mathrm{CI}=0.217$ to $0.416, \eta^{2}=0.495$ ) and Difficulty $\left[\left(\mathrm{B}=0.312, \mathrm{p}<0.001,95 \% \mathrm{CI}=0.211\right.\right.$ to $\left.0.412, \eta^{2}=0.482\right)$, indicating that as experience increased, athletes' performance also increased. 

WHICH FACTORS ARE INFLUENCING ARTISTIC SWIMMING PERFORMANCE?

Table 2: Follow-up ANOVAs with Bonferroni correction for Category on Execution, Artistic Impression, and Difficulty (adjusted for Experience and Rhythmic Ability)

\begin{tabular}{|c|c|c|c|c|c|c|}
\hline Variables & Category (n) & M $(95 \% \mathrm{CI})$ & $\mathrm{SE}$ & F & $\mathrm{p}$ & partial $\eta^{2}$ \\
\hline \multirow{3}{*}{ Execution } & Senior (9) & $6.20(5.50-6.89)$ & 0.34 & \multirow{3}{*}{1.745} & \multirow{3}{*}{0.187} & \multirow{3}{*}{0.077} \\
\hline & Junior (7) & $5.72(5.15-6.28)$ & 0.28 & & & \\
\hline & Comen (31) & $6.29(6.00-6.58)$ & 0.14 & & & \\
\hline \multirow{3}{*}{ Artistic Impression } & Senior & $6.32(5.64-7.01)$ & 0.34 & \multirow{3}{*}{1.990} & \multirow{3}{*}{0.149} & \multirow{3}{*}{0.087} \\
\hline & Junior & $5.70(5.14-6.25)$ & 0.28 & & & \\
\hline & Comen & $6.28(6.00-6.57)$ & 0.14 & & & \\
\hline \multirow{3}{*}{ Difficulty } & Senior & $6.26(5.57-6.95)$ & 0.34 & \multirow{3}{*}{2.061} & \multirow{3}{*}{0.140} & \multirow{3}{*}{0.089} \\
\hline & Junior & $5.66(5.01-6.22)$ & 0.28 & & & \\
\hline & Comen & $6.27(5.98-6.55)$ & 0.14 & & & \\
\hline
\end{tabular}

For the second MANCOVA, the Box-M test of equality of covariance for the MANCOVA was not statistically significant (Box's $M=21.006, p=0.187$ ) and the assumption that variance/covariance matrices are equal across two or more groups was met. The MANCOVA indicated that no statistically significant differences were observed between Categories [Pillai's Trace $=0.160, \mathrm{~F}(4,86)=1.864, \mathrm{p}=0.124, \eta^{2}=0.080$ ] on the two dependent variables (Table 3). Experience, as covariate was a statistically significantly predictor of the two variables [Pillai's Trace $=0.534, \mathrm{~F}(2,42)=24.057, \mathrm{p}<0.001, \eta^{2}=0.534$ ], with large effect size. More specifically, Experience was a positive predictor of AS Performance $(B=0.311$, $\mathrm{p}<0.001,95 \% \mathrm{CI}=0.216$ to $\left.0.405, \eta^{2}=0.506\right)$ and $\mathrm{RA}(\mathrm{B}=0.227, \mathrm{p}=0.050,95 \% \mathrm{CI}=0.001$ to 0.454 , $\eta^{2}=0.087$ ), indicating that as experience increased, athletes' AS performance and RA also increased.

Table 3: Follow-up ANOVAs with Bonferroni correction for Category on Rhythmic Ability and Artistic Swimming Performance (adjusted for Experience)

\begin{tabular}{|c|c|c|c|c|c|c|}
\hline Variables & Category (n) & M $(95 \% \mathrm{CI})$ & SE & $\mathbf{F}$ & p & partial $\eta^{2}$ \\
\hline \multirow{3}{*}{ Rhythmic Ability } & Senior (9) & $22.66(21.04-24.28)$ & 0.80 & \multirow{3}{*}{1.888} & \multirow{3}{*}{0.164} & \multirow{3}{*}{0.081} \\
\hline & Junior (7) & $21.03(19.76-22.31)$ & 0.63 & & & \\
\hline & Comen (31) & $22.27(21.60-22.94)$ & 0.14 & & & \\
\hline \multirow{3}{*}{ Artistic Swimming Performance } & Senior & $6.40(5.73-7.08)$ & 0.33 & \multirow{3}{*}{2.021} & \multirow{3}{*}{0.145} & \multirow{3}{*}{0.086} \\
\hline & Junior & $5.84(5.31-6.37)$ & 0.26 & & & \\
\hline & Comen & $6.41(6.13-6.69)$ & 0.14 & & & \\
\hline
\end{tabular}

\section{Discussion}

Artistic swimming is "a difficult sport, requiring many hours and years of practice in order to participate in a handful of contests and competitions each year with a program ranging from two to four minutes according to the competition category and the athletic event" (Ntomali et al., 2017, pp. 29-30). Successful performance depends on the swimmers' ability to execute a synchronized routine of elaborate moves in the water accompanied by music (RodríguezZamora et al., 2014). Depending on age and competitive level, AS novice athletes practice 1-2 hours for 3 pool sessions per week. In elite level athletes, high-volume practice can be approximately 40 hours per week (Mountjoy, 2009; Rodríguez-Zamora et al., 2012). This 
is the main reason that dropout rates are increasing with age due to increased educational obligations. In the current study, the majority of athletes were in the comen category, followed by seniors and juniors.

The existing literature indicates the role and importance of rhythm in several sports (Borysiuk \& Waskiewicz, 2008; Das, 2013; Bago et al., 2013; Oreb et al., 2011; Thapa et al., 2016; Vaculíková et al., 2011). In AS, athletes should precisely synchronize choreography with both their teammates and music (Robertson et al., 2014). As it is already mentioned, RA and synchronization are included in the evaluation criteria (Chairopoulou, 2010; Mountjoy, 2009). Furthermore, the judging system evaluates components of technical skill, synchronization, and artistic impression (Robertson \& Mountjoy, 2018). Until now the relationship between RA and performance in AS has not yet been investigated. According to the results of the present study, RA and competitive category could not differentiate athletes with different level of AS performance. The only significant predictor of AS performance was participants' overall experience, measured in years. Even though athletes in the senior category performed better in all estimated parameters (i.e., AS performance, RA, Execution, Artistic impression and Difficulty), the moderating effect of experience was so evident, that all differences between the various competitive categories were minimized. RA is not the only factor to satisfy high score in a routine. Athletes of AS have to possess and other characteristics as such the level, the athletic and competitive experience, the quality of training, the technic, the high level of coordination, the psychological characteristics etc.

Oreb and Kilibarda (1996) found that there was significant relationship between rhythmic abilities and performance in dance, and therefore it was possible to estimate dance performance based on the evaluation of rhythmic abilities. This was not supported by the results of the present study. Current findings suggest that AS performance was not related to RA and the competitive categories of the athletes. As it is mentioned above only athletes experience was found to be a significant factor for both AS swimmers' performance and their scores in RA test.

In AS, Greek athletes begin their athletic career early in life and take part in various competitions from the age of eight. According to Mountjoy (1999) most AS swimmers enter the sport as young girls at the recreational level and by the age of 13 to 15 years, the more hard-working and/or talented athletes may choose to train and compete at a more intense and higher level. Thus, it is logical to have more years of experience, resulting in participating in more competitions as they become older, as they move in higher categories. A competitive year includes the minimum of 4 competitive trials for AS athletes. This means that they have trained uncountable hours in routines that contain different figures and music. We conclude that the rise of experience leads to an improvement in rhythmic abilities and athletic performance. This approach can potentially be supported by the present findings, however further research is definitely needed towards this direction. Also, a previous study supported that to achieve the desired performance outcomes, AS athletes have to train for many hours in various exercise modalities (Mountjoy, 2009). Thus, although previous research revealed that RA was better as the age increased (Haskell, 1993; Kumai \& Sugai, 1997; Rainbow, 1981; 
Rosenbusch \& Gardner, 1968; Schleuter \& Schleuter, 1985), in our study it has been found that experience plays a more important than age at RA improvement. This result is not consistent with previous findings, and it might be attributed to the different and uneven sample size used, which is a result of most athletes dropping off from competitive AS as they grow older.

In addition, results showed that athletes in the senior category scored higher in all variables in relation to junior and comen athletes; however, these differences were not statistically significant. More specifically, the total score $(M=8.01, S D=0.81)$ that senior athletes received during routine session was higher in an AS competition compared to junior $(M=5.60, S D=0.68)$ or comen athletes $(M=6.00, S D=1.05)$. The senior level represents an entirely different competitive level. Similarly, RA's results also indicate seniors had higher scores compared to the other two categories. Previous studies pointed out that RA development is related to training (Sögüt et al., 2012; Trump, 1987; Weikart, 1989; Zachopoulou \& Mantis, 2001; Zachopoulou et al., 2003), and well-trained and highperformance athletes were accurate in kinetic skills during rhythmical stimuli and had well-developed RA (Benton, 1944; Haight, 1944; Huff, 1972; Segal, 2005). It seems that older athletes in our study were more experienced, which according to the results was a positive predictor of AS Performance and RA, indicating that as experience increased, athletes' AS performance and RA also increased. We believe the reason for this is that senior athletes have participated in many different events with a variety of choreographies, musical pieces, and rhythmic patterns. This further means that senior athletes have trained in slow and fast rhythmic patterns to achieve a routine of high standards, which might have influenced their experience.

\section{Conclusion}

This study investigated RA's relationship with the athletes' performance in AS, taking into account their competitive category and previous athletic experience. It highlighted the significance of athletic experience, as this variable was a significantly positive predictor of both RA and AS Performance. Thus, it is suggested that coaches should reinforce their athletes to participate in many competitions to gain experience and, consequently, improve their RA and AS performance. Since the results of the current study are limited to AS, future studies are recommended to explore the aforementioned relationship to different sports, age or gender.

In conclusion, this is the first study to examine athletes' RA in relation to athletic performance, competitive category and athletic experience in the sport of AS. The fact that there were few athletes if high level in this study, or bigger competitive categories, is one limitation of the study.

\section{Conflicts of interest}

The authors declare that there are no conflicts of interest. 


\section{About the Author(s)}

Stavroula Ntomali ${ }^{1}$ (PhD), Specialized educational staff, Section of Aquatic Sports, School of Physical Education \& Sports Science, National and Kapodistrian University of Athens, Greece, Email: sdomali@phed.uoa.gr

Manolis Adamakis'2, Lecturer in Physical Education, School of Education, University College Cork, Ireland, Email: manosadam@phed.uoa.gr

Fotini Venetsanou ${ }^{1}$, Associate Professor, Section of Gymnastics and Dance, School of Physical Education \& Sports Science, National and Kapodistrian University of Athens, Greece, Email: fvenetsanou@phed.uoa.gr

Chrysoula Chairopoulou ${ }^{1}$, Associate Professor, Section of Aquatic Sports, School of Physical Education \& Sports Science, National and Kapodistrian University of Athens, Greece, Email: cchairop@phed.uoa.gr

Maria Psychountaki ${ }^{1}$, Professor of Psychology-Sport Psychology, School of Physical Education \& Sports Science, National and Kapodistrian University of Athens, Greece, Email: mpsychou@phed.uoa.gr

${ }^{1}$ School of Physical Education \& Sports Science, National and Kapodistrian University of Athens, Greece. Address: Ethnikis Antistasis 41, 17237, Daphne, Athens, Greece.

${ }^{2}$ School of Education, University College Cork, Ireland. Address: School of Education, University College Cork, Leeholme, O' Donovan's Road, Cork, Ireland.

\section{Correspondence}

Stavroula Ntomali, School of Physical Education \& Sports Science, National and Kapodistrian University of Athens, Ethnikis Antistasis 41, 17237, Daphne, Athens, Greece. E-mail: sdomali@phed.uoa.gr

\section{References}

Agdiniotis, I., Pollatou, E., Zisi, V., Gerodimos, V., \& Giagoudaki, T. (2009). Relationship between rhythmic ability and type of motor activities in preschool children. European Psychomotricity Journal, 2(1), 24-34.

Ateş, C., Kaymaz, Ö., Kale, H. E., \& Tekindal, M. A. (2019). Comparison of test statistics of nonnormal and unbalanced samples for multivariate analysis of variance in terms of type-I error rates. Computational and Mathematical Methods in Medicine, 2019, 2173638.

Bago, G., Hedbavny, P., \& Kalichova, M. (2013). Talent Selection for Present Conception of Women Sports Gymnastics and Practical Verification of the Test Battery. World Academy of Science, Engineering and Technology - International Journal of Medical Science and Engineering, 7(10), 36-41.

Benton, R. (1944). The measurement of capacities for learning dance movement techniques. Research Quarterly, 15(2), 137-142.

Borysiuk, Z., \& Waskiewicz, Z. (2008). Information processes, stimulation and perceptual training in fencing. Journal of Human Kinetics, 19, 63-82. 
Bourquin, O. (2003). Coordination. In M. Crespo, M. Reid \& D. Miley (Eds.), Applied sport science for high performance tennis. The International Tennis Federation, ITF Ltd, 4951.

Chairopoulou, C. (2010). Coaching of Synchronized Swimming. Athens: Telethrion Publications.

Das, S. (2013). Comparison of rhythmic ability of female soccer players of Tripura state at different levels. International Journal of Physical Education, Health and Social Science, 2(2), 63-64.

Derri, V., Kioumourtzoglou, E., \& Tzetzis, G. (1998). Assessment of abilities in basketball: A preliminary study. Perceptual and Motor Skills, 87, 91-95.

Derri, V., Tsapakidou, A., Zachopoulou, E., \& Gini, V. (2001). Complexity of rhythmic ability as measured in preschool children. Perceptual and Motor Skills, 92, 777-785.

Ellis, M. C. (1992). Tempo perception and performance of elementary students, grades 3 - 6. Journal of Research in Music Education, 40(4), 329 - 341.

FINA Handbook (2017). Fina Artistic Swimming Rules 2017-2021 (pp. 1-98). Federation Internationale de Natation.

Haight, E. (1944). Individual differences in motor adaptations to rhythmic stimuli. Research Quarterly, 15, 38-43

Haskell, L. (1993). Rehabilitation therapists tap into new rhythms for life. Advance for Physical Therapists, 4(5), 24-26.

Huff, J. (1972). Auditory and visual perception of rhythm by performers skilled in selected motor activities. Research Quarterly, 43(2), 197-207.

Kiger, J. (1994). Relationships among the development of fundamental motor skills, basic timing, and academic performance in elementary school age children. Dissertation Abstracts International, 78, 5680B.

Kioumourtzoglou, E., Derri, V., Tzetzis, G., \& Theodorakis, I. (1998). Cognitive, perceptual and motor abilities in skill basketball performance. Perceptual and Motor Skills, 86, 771-786.

Kirchner, G., \& Fishburne G. J. (1995). Physical education for elementary school children (9 ${ }^{\text {th }}$ ed.). WCB Brown and Benchmark Publishers, Dubuque, IA.

Kuhlman, K., \& Schweinhart, L. (1999). Timing in child development. Ypsilanti, MI: High/Scope Educational Research Foundation.

Kumai, M., \& Sugai, K. (1997). Relation between synchronized and self-paced response in preschoolers' rhythmic movement. Perceptual and Motor Skills, 85(3), 1327-1337.

Laurence, P. C. (2000). The role of rhythm in ballet training. Research in Dance Education, 1, 173-191.

Liapa, E. (2004). Study of rhythmic ability of High School students who are involved in motor activities accompanied or not by music. Master Thesis, DPESS - Democritus University of Thrace and University of Thessaly.

Mastrokalou, N., \& Hatziharistos, D. (2007). Rhythmic ability in children and the effects of age, sex and tempo. Perceptual and Motor Skills, 104, 901-912.

Mountjoy, M. (1999). The basics of synchronized swimming and its injuries. Clinics in Sports Medicine, 18(2), 321-336. 
Mountjoy, M. (2009). Injuries and medical issues in synchronized Olympic sports. Current Sports Medicine Reports, 8(5), 255-261.

Ntomali, S., Psychountaki, M., Kyprianou, M., \& Chairopoulou, C. (2017). The moderation effect of maturity on the association between perceived leadership behavior and athlete satisfaction. International Journal of Psychological Studies, 9(4), 24-32.

Olson, C. L. (1974). Comparative robustness of six tests in multivariate analysis of variance. Journal of the American Statistical Association, 69(348), 894-908.

Oreb, G., \& Kilibarda, S. (1996). The role of rhythmic abilities in dance. Kinesiology, 28(1), 58-63.

Oreb, G., Vlasic, J., Cigrovski, V., Prlenda, N., \& Radman, I. (2011). Relationship between rhythm and learning alpine skiing technique. Conference: 6th FIEP European congress (pp. 640-646), Porec, Croatia.

Pica, R. (1998). Dance training for gymnastics. Leisure Press Champaign: IL.

Pollatou, E., Liapa, E., Diggelidis, N., \& Zachopoulou, E. (2005). Measure of rhythmic ability in high school students who are involved in motor activities accompanied or not by music. Inquiries in Sport E Physical Education, 3(1), 22-28.

Rainbow, E. (1981). A final report on a three-year investigation of the rhythmic ability of pre-school aged children. Bulletin of the Council for the Research in Music Education, 66/67, 69-73.

Rao, S. M., Mayer, A. R., \& Harrington, D. L. (2001). The evolution of brain activation during temporal processing. Nature Neuroscience, 4(3), 317-323.

Robertson, S., Benardot, D., \& Mountjoy, M. (2014). Nutritional recommendations for synchronized swimming. International Journal of Sport Nutrition and Exercise Metabolism, 24, 404-413.

Robertson, S., \& Mountjoy, M. (2018). A Review of Prevention, Diagnosis, and Treatment of Relative Energy Deficiency in Sport in Artistic (Synchronized) Swimming. International Journal of Sport Nutrition and Exercise Metabolism, 28(4), 375-384

Rodríguez-Zamora, L., Iglesias, X., Barrero, A., Chaverri, D., Erola, P., \& Rodríguez, F. A. (2012). Physiological responses in relation to performance during competition in elite synchronized swimmers. PLoS One, 7(11):e49098.

Rodríguez-Zamora, L., Iglesias, X., Barrero, A., Torres, L., Chaverri, D., \& Rodríguez, F. A. (2014). Monitoring internal load parameters during competitive synchronized swimming duet routines in elite athletes. Journal of Strength and Conditioning Research, 28(3), 742-51.

Rosenbusch, M., \& Gardner, D. (1968). Reproduction of visual and auditory rhythm patterns by children. Perceptual and Motor Skills, 26, 1271-1276.

Sardar, B., \& Verma, K. (2014). Rhythmic Ability of Handball Players at Outstanding Level of Performance: A Virtual Study. Asian Journal of Multidisciplinary Studies, 2(9), 34-36.

Schleuter, S., \& Schleuter, L. (1985). The relationship of grade level and sex differences to certain rhythmic responses of primary grade children. Journal of Research in Music Education, 33(1), 23-29. 
Schönborn, R. (2003). Timing in tennis: New findings and conclusions. In M. Crespo, M. Reid \& D. Miley (Eds.), Applied Sport Science for High Performance Tennis (pp. 3739). The International Tennis Federation, ITF Ltd.

Schwanda, N. (1969). A study of rhythmic ability and movement performance. Research Quarterly, 40(3), 567-574.

Segal, D. K. (2005). Tennis biodynamic system: For the teaching and correction of tennis shots. Destino Global Sports Marketing: Buenos Aires.

Söğüt, M., \& Kirazci, S. (2014). Sport Participation and Gender Differences in Rhythmic Ability. Journal of Sport Sciences, 25(1), 36-42.

Söğüt, M., Kirazci, S., \& Korkusuz, F. (2012). The Effects of Rhythm Training on Tennis Performance. Journal of Human Kinetics, 33, 123-132. Section III - Sports Training.

Southard, D., \& Miracle, A. (1993). Rhythmicity, ritual and motor performance: A study of free throw shooting in basketball. Research Quarterly for Exercise and Sport, 64, 284-290.

Tabachnick, B. G., \& Fidell, L. S. (2013). Using Multivariate Statistics (6 ${ }^{\text {th }}$ ed.). Boston, MA: Pearson.

Takahata, M., Shiraki, K., Sakane, Y., \& Takebayashi, Y. (2004). Sound feedback for powerful karate training. In Proceedings of the 2004 conference on New interfaces for musical expression (pp. 13-18). National University of Singapore.

Thapa, S., Bharali, J., Baro, M., Singh, O. J., \& Singh, L. S. (2016). Comparative study on eye foot co-ordination and rhythmic ability between selected folk dancers and racquet sports players. International Journal of Physical Education, Sports and Health, 3(6), 268-270.

Thomas, J., \& Moon, D. (1976). Measuring motor rhythmic ability in children, Research Quarterly, 47(1), 20-32.

Trump, P. (1987). Effects of Weikart's sequential approach to Rhythmic movement on development of rhythmic competency in primary age children. Dissertation Abstracts International, 67, 8745A, Drake University.

Vaculíková, P., Svobodová, L., Šimberová, D., \& Honková K. (2011). Analysis of the relationship rhythmic execution and rhythmic perception in dance sport. Studia Sportiva, 5(2), 43-50.

Warner, R. M. (2013). Applied statistics: From bivariate through multivariate techniques (2 ${ }^{\text {nd }}$ ed.). Thousand Oaks, California: Sage Publications, Inc.

Weikart, P. (1989). Teaching movement and dance. Ypsilanti, Michigan: High/Scope Press.

Weikart, P., Schweinhart, L., \& Lamer, M. (1987). Movement curriculum improves children's rhythmic competency, study shows. High/scope Resource, 6(1), 8-10.

Wrisberg, C., \& Pein, L. (1992). The pre-shot interval and free throw shooting accuracy: An explanatory investigation. The Sport Psychologist, 6, 14-23.

Zachopoulou, E. (1998). The effect of rhythmic ability on motor skills performance. Unpublished Dissertation, DPESS - Democritus University of Thrace.

Zachopoulou, E., Derri, V., Chatzopoulos, D., \& Ellinoudis, T. (2003). Application of Orff and Dalcroze activities in preschool children: Do they affect the level of rhythmic ability? The Physical Educator, 60(2), 50-56. 
Zachopoulou, E., Kioumourtzoglou, E., Mantis, K., \& Taxildaris, K. (1999). The effect of rhythm practice method on basketball skills performance during childhood. Athletic Performance and Health, 2, 141-150.

Zachopoulou, E., \& Mantis, K. (2001). The role of rhythmic ability on the forehand performance in tennis. European Journal of Physical Education, 6, 117-126.

Zachopoulou, E., Mantis, K., Serbezis, V., Teodosiou, A., \& Papadimitriou, K. (2000). Differentiation of parameters for rhythmic ability among young tennis players, basketball players and swimmers. European Journal of Physical Education, 5(2), 220230. 
Stavroula Ntomali, Manolis Adamakis, Fotini Venetsanou, Chrysoula Chairopoulou, Maria Psychountaki WHICH FACTORS ARE INFLUENCING ARTISTIC SWIMMING PERFORMANCE?

Creative Commons licensing terms

Authors will retain the copyright of their published articles agreeing that a Creative Commons Attribution 4.0 International License (CC BY 4.0) terms will be applied to their work. Under the terms of this license, no permission is required from the author(s) or publisher for members of the community to copy, distribute, transmit or adapt the article content, providing a proper, prominent and unambiguous attribution to the authors in a manner that makes clear that the materials are being reused under permission of a Creative Commons License. Views, opinions and conclusions expressed in this research article are views, opinions and conclusions of the author(s). Open Access Publishing Group and European Journal of Physical Education and Sport Science shall not be responsible or answerable for any loss, damage or liability caused in relation to/arising out of conflict of interests, copyright violations and inappropriate or inaccurate use of any kind content related or integrated on the research work. All the published works are meeting the Open Access Publishing requirements and can be freely accessed, shared, modified, distributed and used in educational, commercial and non-commercial purposes under a Creative Commons attribution 4.0 International License (CC BY 4.0). 